\title{
Doses de paraquat e volumes de calda na dessecação de Brachiaria ruziziensis antes do cultivo do milho safrinha ${ }^{1}$
}

\author{
Paraquat doses and spray volumes in desiccation Brachiaria ruziziensis before \\ planting off-season maize
}

\section{Neumárcio Vilanova Costa ${ }^{2}$; Daniel Adriano Sontag ${ }^{3}$; Cesar Augusto Scariot ${ }^{3}$; Gabriel Rohrer Pereira $^{4}$; Edmar Soares Vasconcelos ${ }^{2}$}

Resumo - A Brachiaria ruziziensis pode contribuir na consolidação do sistema de plantio devido à alta produção de biomassa vegetal que pode ser empregada no manejo integrado das plantas daninhas. Contudo, existe escassez de informações referentes à dessecação desta forrageira, principalmente com o uso de herbicidas de ação de contato. Assim, objetivou-se avaliar diferentes métodos de manejo da dessecação da forrageira B. ruziziensis, e o efeito na cultura do milho safrinha e na supressão das plantas daninhas. O delineamento experimental utilizado foi o de blocos casualizados, com quatro repetições. Os tratamentos foram dispostos num esquema fatorial 4 x 6 +1 , correspondente a avaliação de quatro doses do paraquat $\left(100,200,400\right.$ e $\left.800 \mathrm{~g} \mathrm{ha}^{-1}\right)$ em seis volumes de aplicação $\left(69,138,204,273,342\right.$ e $\left.411 \mathrm{~L} \mathrm{ha}^{-1}\right)$, além de uma testemunha sem aplicação. Para o estudo da dinâmica da população das plantas daninhas também foi utilizada uma testemunha em condição de pousio e outra somente com a cultura sem a presença de palha (capinada). Foram utilizadas pontas de pulverização modelo Turbo Teejet de jato plano simples com angulação de $90^{\circ}$. O paraquat foi eficiente na dessecação da B. ruziziensis até aos 14 dias após a aplicação. Após este período a rebrota da forrageira interferiu negativamente na produtividade do milho safrinha. A infestação das plantas daninhas foi reduzida nas áreas com B. ruziziensis em consórcio com o milho safrinha em relação à área em pousio.

Palavras-chaves: herbicida, plantio direto, manejo integrado, integração lavoura-pecuária

\begin{abstract}
Brachiaria ruziziensis can contribute to the consolidation of the no-tillage system due to high production of biomass that can be used in integrated management of weeds. However, there is little information regarding the desiccation of this forage, particularly with the use of contact action herbicides. The present work aimed to evaluate the different management methods of desiccation of B. ruziziensis, and the effect in second season maize crop and weed suppression. The experimental design was a randomized complete block design with four replications. The treatments were arranged in a factorial $4 \times 6+1$, corresponding to evaluation of four doses of paraquat $\left(100,200,400\right.$, and $\left.800 \mathrm{~g} \mathrm{ha}^{-1}\right)$, six spraying volumes $(69,138,204,273,342$, and $411 \mathrm{~L}$

\footnotetext{
${ }^{1}$ Recebido para publicação em 29/05/2014 e aceito em 08/07/2015.

${ }^{2}$ Docentes do Centro de Ciência Agrárias da Universidade Estadual do Oeste do Paraná (Unioeste), Rua Pernambuco, C.P. 91, CEP 85960-000, Marechal Cândido Rondon, PR. E-mail: neumarcio.costa@unioeste.br. (*autor para correspondência)

${ }^{3}$ Discentes do curso de Agronomia da Universidade Estadual do Oeste do Paraná (Unioeste). Marechal Cândido Rondon, PR.

${ }^{4}$ Mestrando do Programa de Pós-graduação em Agronomia da Unioeste - (PPGA). Marechal Cândido Rondon, PR.
} 
$\mathrm{ha}^{-1}$ ), and an untreated control. To study the population dynamics of weeds a control was also used in fallow condition and another with only the crop, without the presence of straw (weeded). The spray nozzle used was Turbo TeeJet simple plan jet with angulation of $90^{\circ}$. The paraquat was efficient in desiccation B. ruziziensis up to 14 days after application. After this period there was regrowth of forage plants interfered negatively on maize yiled. The weed infestation was reduced in areas with $B$. ruziziensis in crop rotation with maize in relation to fallowing areas.

Keywords: herbicide, no-tillage, integrated management, crop-livestock integration

\section{Introdução}

O sistema de plantio direto tem se apresentado muito mais que um método de conservação do solo e vem contribuindo para a sustentabilidade da agricultura, mantendo altas produções, sem danificar o solo e o meio ambiente (Amaral, 2001; Mello et al., 2004).

Dentre as propostas que podem colaborar para a consolidação do sistema de plantio direto e proporcionar maior sustentabilidade aos sistemas agrícolas que está sendo amplamente difundida refere-se ao sistema de integração agricultura-pecuária. Neste sistema, ocorre o cultivo consorciado de forrageiras tropicais, em especial as espécies do gênero Brachiaria, com culturas como arroz, feijão, milho, soja e sorgo (Portes et al., 2000; Jakelaitis et al., 2004; Freitas et al., 2005; Jakelaitis et al., 2005a; Severino et al., 2006a).

A Brachiaria ruziziensis Germain e Evrard apresenta elevando potencial de utilização no sistema de integração agriculturapecuária. Esta espécie é nativa na parte oriental da República do Zaire, em Ruanda e Kenya, sendo introduzida como forrageira em diversas partes do mundo, inclusive no Brasil (Kissmann e Groth, 1997).

A semeadura direta é caracterizada pelo reduzido revolvimento do solo e a formação de uma cobertura de restos vegetais sobre a superfície do solo, sendo que a manutenção dos restos vegetais na superfície do solo, além de protegê-lo da radiação solar, dissipa a energia de impacto das gotas de chuva, reduz a evaporação da água e aumenta a eficiência da ciclagem dos nutrientes, podendo ainda modificar e reduzir significativamente a intensidade de infestação de plantas daninhas em áreas agrícolas, devido às alterações das condições de germinação das sementes e emergência das plântulas, em razão do efeito físico da cobertura da palha e/ou da liberação de substâncias alelopáticas (Araújo e Rodrigues, 2000; Severino e Christoffoleti, 2001; Jakelaitis et al., 2003; Mateus et al., 2004).

A capacidade de supressão de plantas daninhas por plantas de cobertura é bastante conhecida e explorada, embora seja pouco pesquisada a importância relativa dos efeitos de natureza física, química e biológica sobre esse fenômeno (Trezzi e Vidal, 2004). No sistema de plantio direto o manejo das forrageiras antes da semeadura é normalmente realizado com herbicidas sistêmicos, contudo herbicidas de contato também podem ser utilizados, a exemplo do paraquat. O paraquat é aplicado em pós-emergência, classificado como não-seletivo e apresenta amplo espectro de ação, o que possibilita excelente controle de plantas daninhas anuais ou perenes, tanto de folhas largas como estreitas. Contudo ainda não apresenta registro de uso para o manejo de dessecação da B. ruziziensis (Rodrigues e Almeida, 2005).

O manejo eficiente das plantas utilizadas como cobertura do solo é um dos fatores mais importantes para o sucesso do estabelecimento de culturas graníferas, pois permite que a cultura se desenvolva inicialmente livre de interferências. Entretanto, a ocorrência de falhas na dessecação pode levar a menor eficiência e rendimento da semeadora, principalmente pela dificuldade de corte da palhada, que pode causar desuniformidade no estande da cultura (Almeida, 1991). 
A quantidade e a uniformidade de depósitos de no alvo está relacionada ao diâmetro das gotas utilizadas nas operações de pulverizações. Sendo que as gotas de menor diâmetro geralmente proporcionam maior cobertura e penetração no dossel das plantas, em contrapartida, ficam mais suscetíveis a perdas por deriva pelo vento e pela evaporação (Downer et al., 1997; Cunha et al., 2003). Desta maneira, a utilização de pontas de pulverização que proporcionem gotas de diâmetro grande e em volumes que garantam boa cobertura do alvo principalmente quando se utiliza produtos de ação de contato, pode conferir maior eficiência e redução dos riscos de deriva.

Vale ressaltar ainda que atualmente são escassos na literatura, trabalhos científicos que abordem este assunto, principalmente, quanto a informações referentes ao manejo químico de $B$. ruziziensis no período da dessecação.Portanto, como o paraquat apresenta ação de contato nas plantas, as hipóteses do presente trabalho baseiam-se no fato de que para o manejo da dessecação da $B$. ruziziensis, a recomendação da dose deste herbicida pode ser dependente do volume de aplicação utilizado. Além de que, a palhada remanescente pode auxiliar na supressão da emergência das plantas daninhas durante $\mathrm{o}$ desenvolvimento da cultura semelhante aos sistemas de consorciação ou de integração.

O objetivo do presente trabalho foi o de avaliar diferentes métodos de manejo da dessecação da forrageira $B$. ruziziensis, e o efeito na cultura do milho safrinha e na supressão das plantas daninhas.

\section{Material e Métodos}

O presente projeto de pesquisa foi realizado no ano agrícola de 2012/13, na Fazenda Experimental Linha Guará, distante 7,0 $\mathrm{km}$ da Universidade Estadual do Oeste do Paraná (UNIOESTE), campus de Marechal Cândido Rondon, apresentando as seguintes coordenadas: $24^{\circ} 42^{\prime} 30^{\prime}$ 's $\mathrm{S}$ de latitude, $54^{\circ} 21^{\prime} 10^{\prime}$ 'W Grw de longitude e $485 \mathrm{~m}$ de altitude.

O solo da área experimental foi classificado como Latossolo Vermelho Distroférrico (LVdf), de textura argilosa e possui boa drenagem (Embrapa, 1999), cultivado há sete anos no sistema plantio direto na palha. A análise química apresentou as seguintes características: $\mathrm{pH}\left(\mathrm{CaCl}_{2}\right)=4,65$; matéria orgânica $\left(\mathrm{g} \mathrm{dm}^{-3}\right)=20,51 ; \mathrm{P}\left(\mathrm{mg} \mathrm{dm}^{-3}\right)$ $=13,05 ; \mathrm{H}+\mathrm{Al}, \mathrm{K}, \mathrm{Ca}, \mathrm{Mg}, \mathrm{SB}$ e CTC $\left(\mathrm{cmol}_{\mathrm{c}}\right.$ $\left.\mathrm{dm}^{-3}\right)=4,70 ; 0,38 ; 4,34 ; 1,77 ; 6,49$ e 11,$19 ;$ respectivamente; e V\% $=58,00$; tendo em sua composição textural $10,79 \%$ de areia; $36,21 \%$ de silte e 53,00\% de argila.

No experimento, utilizou-se o delineamento experimental de blocos casualizados com quatro repetições. Os tratamentos foram dispostos num esquema fatorial $4 \times 6+1$, correspondente a avaliação de quatro doses do paraquat $(100,200,400$ e $800 \mathrm{~g}$ $\mathrm{ha}^{-1}$ de ingrediente ativo) em seis volumes de aplicação (69, 138, 204, 273, 342 e $\left.411 \mathrm{~L} \mathrm{ha}^{-1}\right)$, além de uma testemunha sem aplicação. Para o estudo da dinâmica da população das plantas daninhas também foi utilizada uma testemunha em condição de pousio e outra somente com a cultura sem a presença de palha (capinada).

Foram utilizados pontas de pulverização modelo Turbo Teejet de jato plano simples com angulação de $90^{\circ}$. As descrições das pontas de pulverização utilizadas para a obtenção dos volumes de aplicação estão descritas na Tabela 1.A dessecação da área foi realizada com o herbicida glyphosate na dose de $900 \mathrm{~g} \mathrm{ha}^{-1}$ (Glifosato Atanor, $360 \mathrm{~g} \mathrm{~L}^{-1}$ do equivalente ácido), 30 dias antes do plantio da Brachiaria ruziziensis.

A semeadura da B. ruziziensis (27/11/2012) foi realizada utilizando-se uma semeadoura adaptada para o plantio de sementes de pastagem (COPAGRIL).Utilizou-se sementes incrustadas com germinação de $60 \%$ que foram misturadas ao adubo Super Fosfato Simples com $18 \%$ de $\mathrm{P}_{2} \mathrm{O}_{5}$ (155 kg ha ${ }^{-1}$ de SFS) para a distribuição de $10,0 \mathrm{~kg} \mathrm{ha}^{-1}$ de sementes 
da forrageira. O manejo das plantas daninhas antes da aplicação dos tratamentos foi realizado por meio de capinas manuais.

A aplicação dos tratamentos foi realizada em 09/02/2013 quando a braquiária apresentava pleno desenvolvimento $(1,10 \pm 0,2$ $\mathrm{m}$ de altura e antes do florescimento) e cobriu totalmente a superfície do solo das unidades experimentais, sendo que a quantidade de massa seca correspondeu a 14.111,8 $\mathrm{kg} \mathrm{ha}^{-1}$. Para a determinação da biomassa da forrageira antes da instalação do experimento foi coletada a parte aérea das plantas em parcelas específicas para este fim, utilizando-se uma moldura metálica de $0,25 \mathrm{~m}^{2}$ de área, em uma amostragem por unidade experimental. $\mathrm{O}$ material coletado foi seco em estufa de circulação forçada de ar a $60^{\circ} \mathrm{C}$; em seguida, pesado, e os dados, transformados em kg ha ${ }^{-1}$.

Tabela 1. Descrição das pontas de pulverização que foram utilizadas no experimento, para o manejo da dessecação da B. ruziziensis com diferentes doses do paraquat.

\begin{tabular}{|c|c|c|c|c|c|}
\hline \multirow[t]{2}{*}{ Ponta* } & \multirow[t]{2}{*}{ Descrição } & $\begin{array}{l}\text { Volume de } \\
\text { Aplicação }\end{array}$ & Pressão & Velocidade & \multirow[t]{2}{*}{ Classificação das gotas } \\
\hline & & $\mathrm{L} \mathrm{ha}^{-1}$ & $\mathrm{KPa}$ & $\mathrm{km} \mathrm{h}^{-1}$ & \\
\hline Turbo Teejet & TT11001VP & 69 & 100 & 4,0 & Grossa \\
\hline Turbo Teejet & TT11002VP & 138 & 100 & 4,0 & Grossa \\
\hline Turbo Teejet & TT11003VP & 204 & 100 & 4,0 & Muito grossa \\
\hline Turbo Teejet & TT11004VP & 273 & 100 & 4,0 & Extremamente grossa \\
\hline Turbo Teejet & TT11005VP & 342 & 100 & 4,0 & Extremamente grossa \\
\hline Turbo Teejet & TT11006VP & 411 & 100 & 4,0 & Extremamente grossa \\
\hline
\end{tabular}

Para a aplicação dos tratamentos, foi utilizado pulverizador costal pressurizado a $\mathrm{CO}_{2}$, com pressão constante, equipado com seis pontas, espaçadas em $0,5 \mathrm{~m}$ e posicionadas a 0,5 $\mathrm{m}$ do alvo. As aplicações foram realizadas no período da tarde com condições climáticas de 28,7 a $33,2^{\circ} \mathrm{C}, 47$ a $54 \%$ de umidade relativa do ar e 0,9 a1,9 $\mathrm{m} \mathrm{s}^{-1}$ de velocidade do vento.

O milho safrinha (Pioneer 30F53 Hx) foi semeado em 18/02/2013, no espaçamento de $0,75 \mathrm{~m}$. A adubação de base foi de $400 \mathrm{~kg} \mathrm{ha}^{-1}$ do formulado 8-20-20. Aos 45 dias após o plantio foi realizada a adubação de cobertura (60 $\mathrm{kg} \mathrm{ha}{ }^{-1}$ de ureia $-45 \%$ de nitrogênio) distribuindo-se manualmente na linha de plantio do milho. Cada unidade experimental foi constituída de quatro linhas, em uma área total de $15,0 \mathrm{~m}^{2}$ (3 $\mathrm{m}$ de largura $\mathrm{x} 5 \mathrm{~m}$ de comprimento). Como área útil considerou-se apenas as duas linhas centrais, desprezando-se $0,5 \mathrm{~m}$ em cada extremidade $\left(6,0 \mathrm{~m}^{2}\right)$.

Avaliação da dessecação da forrageira foi realizada visualmente por meio dos efeitos de intoxicação das plantas de B. ruziziensis, utilizando-se uma escala de percentual de notas, na qual 0 (zero) corresponde a nenhuma injúria demonstrada pela planta e 100 (cem) à morte das plantas, segundo a Sociedade Brasileira da Ciência das Plantas Daninhas - SBCPD (1995). Os parâmetros utilizados para estabelecimento das notas foram: inibição do crescimento, quantidade e uniformidade das injúrias, capacidade de rebrota das plantas, quantidade de plantas mortas e acúmulo de biomassa.

As avaliações de intoxicação foram realizadas aos 3, 7 e 14 dias após a aplicação dos tratamentos (DAA). No $3^{\circ}$ dia após a colheita da cultura (19/08/2013) foi avaliada a massa seca da forrageira, para determinar o acúmulo de biomassa e a quantidade de palhada remanescente na área. Para isso, foi coletada a parte aérea das forrageiras, utilizando-se uma moldura metálica de $0,25 \mathrm{~m}^{2}$ de área, em uma amostragem por unidade experimental. O material coletado foi seco em estufa de 
circulação forçada de ar a $60^{\circ} \mathrm{C}$; em seguida, pesado, e os dados, transformados em $\mathrm{kg} \mathrm{ha}^{-1}$.

$\mathrm{Na}$ cultura do milho safrinha determinou-se a altura das plantas de milho aos 21 dias após semeadura (DAS), por meio de uma régua graduada de 1 metro de altura. A altura das plantas foi determinada pela medida do nível do solo até o ápice da folha mais alta em 5 plantas escolhidas ao acaso nas fileiras centrais da parcela.

Por ocasião da colheita (16/08/2013) determinou-se a densidade de plantas por metro linear e foram colhidas as espigas manualmente das plantas das duas linhas da área útil das parcelas. A colheita do milho safrinha foi feita aos 178 DAS.Após a colheita as espigas foram debulhadas mecanicamente e efetuou-se a limpeza e a correção da umidade dos grãos para $13 \%$.

Aos 183 DAS foi realizada a avaliação da comunidade de plantas daninhas na área de cada tratamento utilizando-se quadros de 0,25 $\mathrm{m}^{2}(0,5 \times 0,5 \mathrm{~m})$, lançados ao acaso em cada parcela. As plantas daninhas foram coletadas e pesadas. O controle em função dos tratamentos foi efetuado por meio de: $\mathrm{C}=[1-(\mathrm{I} / 100)]$, em que C é o controle de plantas daninhas, em \%; e $\mathrm{I}$, a incidência de plantas daninhas $\left(\mathrm{n}^{\mathrm{o}}\right.$ de plantas daninhas observadas por espécie / $\mathrm{n}^{\mathrm{O}}$ de plantas daninhas total), em \%.

Os resultados referentes à porcentagem de dessecação da forrageira, altura de plantas de milho safrinha, densidade de plantas, produtividade de grãos e produção de massa seca da forrageira foram submetidos à análise de variância - ANOVA pelo teste ' $F$ ' $(p \leq 0,05)$, e as médias foram ajustadas a modelos de regressão de superfície de resposta utilizando-se o software SigmaPlot 12.0, sendo as equações escolhidas com base nos modelos significativos $(p \leq 0,05)$ com lógica biológica e de elevado $\mathrm{R}^{2}$.

\section{Resultados e Discussão}

Verificou-se que houve apenas interação entre os fatores doses do paraquat e de volumes de aplicação para a porcentagem de dessecação da forrageira aos 7 e 14 DAA (Tabela 2). Na Figura 1, estão apresentadas as porcentagens de dessecação da B. ruriziensis em diferentes dias após a aplicação do paraquat com distintas doses e de volumes de aplicação.

Tabela 2. Quadrado médio da análise de variância dos parâmetros avaliados no manejo da dessecação da $B$. ruziziensis com diferentes doses do paraquat e de volumes de aplicação antecedendo a semeadura do milho safrinha.

\begin{tabular}{|c|c|c|c|c|c|c|c|}
\hline \multirow{2}{*}{ Fonte de Variação } & \multicolumn{3}{|c|}{ \% de dessecação } & \multirow{2}{*}{$\begin{array}{l}\text { Altura } \\
(\mathrm{cm})\end{array}$} & \multirow{2}{*}{$\begin{array}{l}\text { Densidade } \\
\left(\text { planta } \mathrm{m}^{-1}\right)\end{array}$} & \multirow{2}{*}{$\begin{array}{c}\text { Produtividade } \\
\left(\mathrm{kg} \mathrm{ha}^{-1}\right)\end{array}$} & \multirow{2}{*}{$\begin{array}{c}\mathrm{MS} \\
\left(\mathrm{kg} \mathrm{ha}^{-1}\right)\end{array}$} \\
\hline & $3 \mathrm{DAA}$ & 7DAA & 14DAA & & & & \\
\hline Dose (D) & $4342,42 *$ & $7021,53^{*}$ & $596,28^{*}$ & $2,12^{\mathrm{ns}}$ & $1,21^{\mathrm{ns}}$ & $6913834,90 *$ & $965759,38^{\mathrm{ns}}$ \\
\hline Volus & $495,58 *$ & 783 & 85,9 & 19,5 & 0,2 & 1883962 , & $1379859,41^{\mathrm{ns}}$ \\
\hline & $128,15^{\text {ns }}$ & $187,32 * *$ & $51,68 * *$ & $8,65^{\mathrm{ns}}$ & $0,49^{\text {ns }}$ & $2238705,36^{\mathrm{ns}}$ & $4512917,11^{\mathrm{ns}}$ \\
\hline Exp. xAdic. & $16973,46^{\text {ns }}$ & $20305,98^{\text {ns }}$ & $30495,01^{\text {ns }}$ & $11,08^{\text {ns }}$ & $18,48^{\text {ns }}$ & $75770467,15^{\text {ns }}$ & $24706808,70^{\mathrm{ns}}$ \\
\hline Blocos & 813,72 & 1021,10 & 2,11 & & & & 77640 \\
\hline & & & 26,07 & 8,59 & 0,24 & 1563176,81 & 4195221,18 \\
\hline $\mathrm{CV}(\%)$ & 17,70 & 13,30 & 5,70 & 8,70 & 40,80 & 75,00 & 41,60 \\
\hline
\end{tabular}

**Significativo a $1 \%$ de probabilidade pelo teste ' $\mathrm{F}$ '; *Significativo a $5 \%$ de probabilidade pelo teste ' $\mathrm{F}$ ' e ${ }^{\text {ns }}$ não significativo.

Pode-se verificar aos 3DAA que as doses menores que $200 \mathrm{~g} \mathrm{ha}^{-1}$ do paraquat promoveram eficiência na dessecação das plantas de $60 \%$ de dessecação nas plantas, independente do volume de aplicação utilizado. Enquanto que, eficiência superior a $80 \%$ foram obtidas quando se utilizou doses acima de $493 \mathrm{~g}$ $\mathrm{ha}^{-1}$ de paraquat e de volumes de aplicação de $389 \mathrm{~L} \mathrm{ha}^{-1}$ (Figura 1A).

Aos 7DAA verificou-se que a partir das doses maiores que $319 \mathrm{~g} \mathrm{ha}^{-1}$ de paraquat e de volumes de aplicação maiores que $368 \mathrm{~L} \mathrm{ha}^{-1} \mathrm{a}$ eficiência na dessecação foi superior a $80 \%$, sendo que a medida em que se aumentou a 
concentração do herbicida na calda pode-se reduzir o volume de aplicação (Figura 1B). Ressalta-se que por ocasião deste período foi realizado a semeadura do milho safrinha.

Já aos 14DAA (seis dias após a semeadura da cultura) todas as aplicações demonstraram elevada eficiência na dessecação da B. ruriziensis (Figura 1C). Entretanto, destaca-se que a partir desse período a plantas da forrageira iniciaram a emissão vigorosa de nova brotação e as sementes do milho safrinha ainda não havia iniciado a emergência.
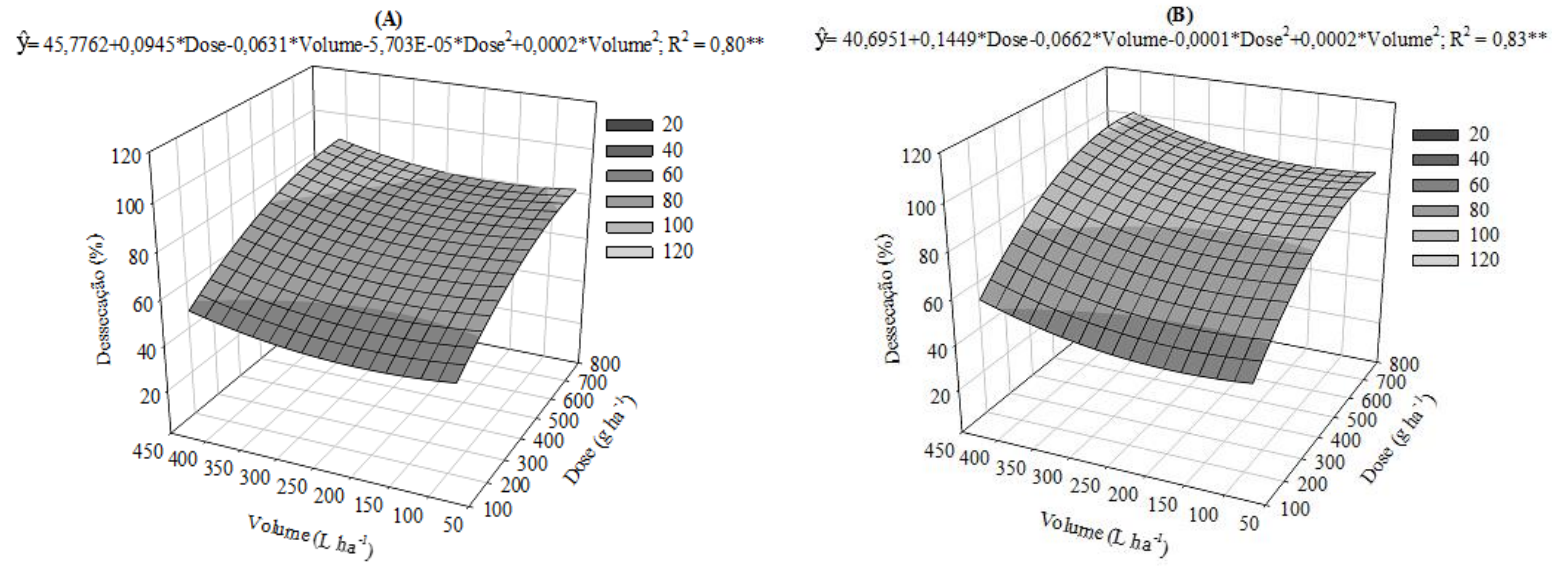

(C)

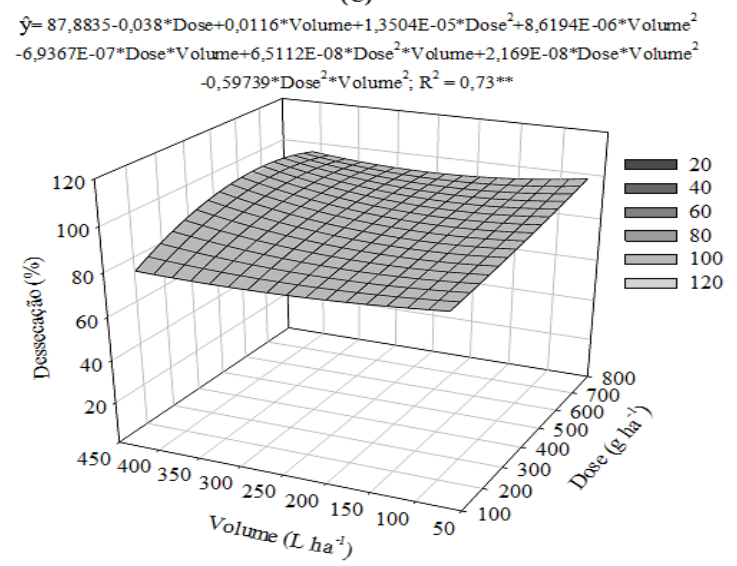

** significativo a $1 \%$ de probabilidade.

Figura 1. Porcentagem de dessecação da B. ruriziensis em diferentes dias após a aplicação do paraquat (DAA) e de volumes de aplicação. 3DAA (A), 7DAA (B) e 14DAA (C).

Segundo Costa et al. (2013), o paraquat aplicado na dose de $800 \mathrm{~g} \mathrm{ha}^{-1}$ no volume de aplicação de $200 \mathrm{~L} \mathrm{ha}^{-1}$ apresentou eficiência de cerca de $80 \%$ até aos 14 DAA na dessecação da B. ruziziensis, contudo, após este período não se observou controle eficiente, visto que as plantas voltaram a emitir folhas novas, o que se explica a diminuição da eficiência da dessecação. Os autores relataram ainda que no momento da aplicação a $B$. ruziziensis estava em pleno desenvolvimento vegetativo, impossibilitando que o herbicida atingisse todas as suas folhas, com requeima apenas nas folhas superiores e apresentando controle satisfatório somente no início das avaliações.

No presente estudo as aplicações dos tratamentos foram realizadas quando as plantas de braquiária apresentavam pleno desenvolvimento e a quantidade de massa seca correspondeu a $14111,8 \mathrm{~kg} \mathrm{ha}^{-1}$. 
Skóra Neto et al. (1995), citam que a mistura de paraquat + diuron $\left(200+100 \mathrm{~g} \mathrm{ha}^{-1}\right)$, promoveram controle inferiores a $60 \%$ da aveiapreta (Avena strigosa) em aplicações com volumes de calda entre 100 a325 $\mathrm{L} \mathrm{ha}^{-1}$. Entretanto, Garcia et al. (2004), verificaram que a dessecação da aveia-preta com a mistura de paraquat + diuron na mesma dose, promoveu controle de 82,5 e $80,3 \%$ quando se utilizou volumes de calda de 300 e $400 \mathrm{~L} \mathrm{ha}^{-1}$, respectivamente.

Já Maciel et al. (2011), citam que a aplicação do paraquat com a adição do adjuvante Silwet ${ }^{\circledR}\left(300 \mathrm{~g} \mathrm{ha}^{-1}+0,1 \% \mathrm{v} \mathrm{v}^{-1}\right)$, no volume de calda de $200 \mathrm{~L} \mathrm{ha}^{-1}$, promoveu controle de 99 e $98 \%$, no manejo de dessecação da $B$. decumbens e $B$. humidicola, respectivamente.

Portanto, o manejo de dessecação da $B$. ruziziensis com o paraquat tende a ser eficiente com o uso de volumes de caldas elevados e/ou de adjuvantes para maximizar a deposição das gotas e consequentemente a absorção do herbicida. Ramsdale e Messersmith (2002), citam que a fitotoxicidade em Avena sativa causada por herbicidas aplicados em elevada doses e concentrações de adjuvantes e em baixos volumes de aplicação pode ser principalmente devido ao aumento da absorção do herbicida em vez da retenção das gotas de pulverização.

Na Tabela 3, estão descritos os dados da altura das plantas de milho safrinha 21 dias após a semeadura. Pode-se verificar que a palhada da B. ruziziensis remanescente não influenciou no crescimento das plantas, bem como a densidade de plantas de milho por ocasião da colheita (Tabela 4).

Tabela 3. Altura das plantas $(\mathrm{cm})$ de milho safrinha 21 dias após a semeadura. A testemunha corresponde ao milho safrinha cultivado sem a presença da palhada da B. ruziziensis.

\begin{tabular}{ccccccc}
\hline \multirow{2}{*}{ Paraquat $\left(\mathrm{g} \mathrm{ha}^{-1}\right)$} & 69 & 138 & 204 & 273 & 342 & 411 \\
\cline { 2 - 7 } & 34,1 & 35,4 & 32,9 & 32,0 & 32,0 & 34,9 \\
200 & 33,5 & 31,8 & 32,7 & 32,6 & 35,7 & 35,5 \\
400 & 35,2 & 31,6 & 35,5 & 31,3 & 35,5 & 33,5 \\
800 & 36,7 & 32,3 & 34,0 & 33,1 & 35,5 & 33,9 \\
\hline Testemunha*ns & \multicolumn{7}{c}{32,1} \\
\hline
\end{tabular}

*A testemunha corresponde ao milho safrinha cultivado sem a presença da palhada da B. ruziziensis. ${ }^{\text {ns }}$ não significativo pelo teste 'F'.

Tabela 4. Densidade de plantas de milho $\left(\right.$ planta $\mathrm{m}^{-1}$ ) por ocasião da colheita.

\begin{tabular}{ccccccc}
\hline \multirow{2}{*}{ Paraquat $\left(\mathrm{g} \mathrm{ha}^{-1}\right)$} & \multicolumn{7}{c}{ Volume de Aplicação (L ha $\left.{ }^{-1}\right)$} \\
\cline { 2 - 6 } & 69 & 138 & 204 & 273 & 342 & 411 \\
\hline 100 & 1,3 & 1,1 & 0,9 & 0,7 & 0,7 & 1,4 \\
200 & 1,0 & 0,9 & 1,0 & 0,8 & 1,5 & 1,3 \\
400 & 1,4 & 0,9 & 1,6 & 1,5 & 1,6 & 1,6 \\
800 & 1,5 & 2,2 & 1,5 & 1,0 & 1,4 & 1,0 \\
\hline Testemunha*ns & \multicolumn{7}{c}{3,4}
\end{tabular}

*A testemunha corresponde ao milho safrinha cultivado sem a presença da palhada da B. ruziziensis. ${ }^{\text {ns }}$ não significativo pelo teste 'F'.

Estes resultados podem justificar a redução da produção de grãos nas parcelas com palhada em relação ao milho safrinha cultivado sem a presença da palha (Figura 2), bem como, ressalta-se a importância da maior eficiência na dessecação da B. ruziziensis para evitar o efeito negativo da palhada no momento da semeadura da cultura (barreira física a germinação das sementes) e da ocorrência de rebrote das plantas (promoção de competição com a cultura). 
Apesar do aumento da produtividade da cultura com o aumento da dose do paraquat, as plantas de $B$ ruziziensis iniciaram a emissão de nova brotação no período da emergência da cultura e consequentemente, este novo ciclo de crescimento da forrageira pode ter interferido no potencial produtivo da cultura do milho safrinha.

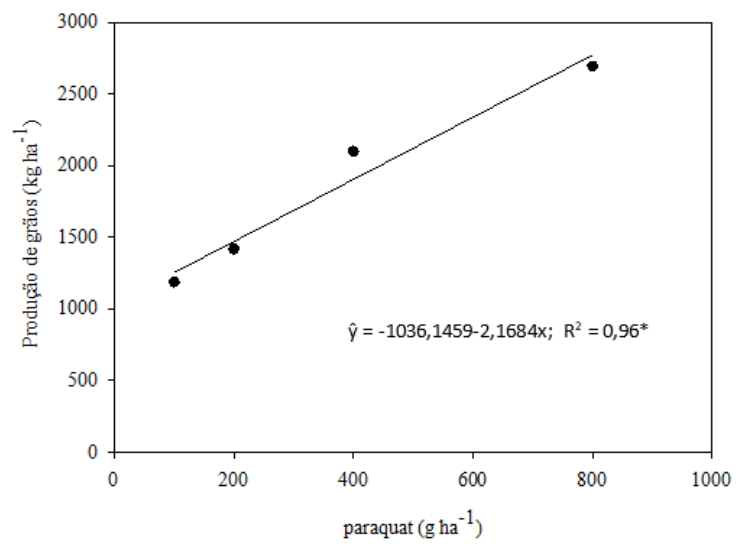

Figura 2. Produção de grãos de milho safrinha após a dessecação da $B$. ruriziensis com diferentes doses de paraquat. A testemunha correspondente ao milho safrinha cultivado sem a presença da palhada da $B$. ruziziensis produziu $6108,17 \mathrm{~kg} \mathrm{ha}^{-1}$.

O desenvolvimento da nova brotação oriunda de plantas dessecadas com paraquat, tende a ser mais prejudicial à cultura do que em relação ao sistema de semeadura simultâneas das espécies. Uma vez que, as plantas com sistema radicular desenvolvido apresentam maior estoque de reservas de energia que podem ser utilizados para a retomada rápida do crescimento em relação as plantas oriundas de sementes. Portanto, estes resultados não corroboram com as hipóteses do presente trabalho de que a recomendação da dose do paraquat para o manejo da dessecação da $B$. ruziziensis, pode ser dependente do volume de aplicação utilizado. Sendo que devido ao rebrote das plantas, talvez seja necessária a aplicação de doses reduzidas de graminicidas para manejar o crescimento da forrageira e, garantir o rendimento da cultura do milho, bem como a formação de palhada para o sistema de plantio direto da cultura subsequente (Dan et al., 2011; Carvalho et al., 2012).

Diversos autores também verificaram que a semeadura da $B$. ruziziensis simultaneamente à do milho não causou reduções na produtividade de grãos (Chioderoli et al., 2010; Garcia et al., 2012; Freitas et al., 2013; Gazola et al., 2013). Estes resultados se devem ao fato de $B$. ruziziensis apresentar crescimento inicial lento e, normalmente, não afetar o crescimento das plântulas de milho, que, contrariamente, possuem crescimento inicial rápido (Freitas et al., 2013).

$\mathrm{Na}$ Tabela 5, pode-se observar que a quantidade de massa seca das plantas de $B$. ruziziensis após a colheita do milho safrinha correspondeu em média de $5.651,6 \mathrm{~kg} \mathrm{ha}^{-1}$ independente do tratamento utilizado. Este fato evidencia o bom potencial das plantas em se recuperar dos efeitos da dessecação causados por herbicidas de ação de contato. Desta forma, não foi possível avaliar o efeito da palhada remanescente no manejo da comunidade das plantas daninhas e sim o efeito da convivência ou do desenvolvimento da forrageira com a cultura do milho safrinha sobre a supressão destas espécies.

Ressalta-se que para os sistemas de cultivos simultâneos, a B. ruziziensis pode requerer mais tempo para formar biomassa suficiente para cobrir o solo. De acordo com Freitas et al. (2013), a massa seca da $B$. ruziziensis aos 60 dias após a colheita do milho variou de 872 a3.378 $\mathrm{kg} \mathrm{ha}^{-1}$ nas densidades de 80.000 a 20.000 plantas $\mathrm{ha}^{-1}$ da cultura, respectivamente. Chioderoli et al. (2010), citam que o consórcio de milho $+B$. ruziziensis semeada na entrelinha foi o que promoveu maior produtividade de massa seca de palha total da forrageira $\left(3.831 \mathrm{~kg} \mathrm{ha}^{-1}\right)$, quando comparado com valores obtidos no consórcio de milho com braquiária semeada na linha (1.509 $\mathrm{kg} \mathrm{ha}^{-1}$ ) e na época de adubação de cobertura $\left(2.247 \mathrm{~kg} \mathrm{ha}^{-1}\right)$. 
Tabela 5. Massa seca $\left(\mathrm{kg} \mathrm{ha}^{-1}\right)$ das plantas de B. ruziziensis por ocasião da colheita do milho safrinha.

\begin{tabular}{ccccccc}
\hline \multirow{2}{*}{ Paraquat $\left(\mathrm{g} \mathrm{ha}^{-1}\right)$} & 69 & 138 & 204 & 273 & 342 & 411 \\
\cline { 2 - 6 } & 4866,1 & 5236,4 & 4456,8 & 5471,7 & 7072,1 & 5122,3 \\
100 & 6061,8 & 5603,1 & 6204,9 & 5584,5 & 4835,5 & 3910,7 \\
400 & 5285,2 & 4834,8 & 4150,6 & 4703,6 & 4767,8 & 6552,4 \\
800 & 5559,5 & 5369,9 & 4525,7 & 3969,7 & 4860,9 & 5753,6 \\
\hline Testemunha*ns & \multicolumn{7}{c}{7464,7} \\
\hline
\end{tabular}

*A testemunha corresponde a forrageira solteira e sem a aplicação do herbicida. ${ }^{\text {ns }}$ não significativo pelo teste ' $\mathrm{F}$ '.

Verificou-se que a presença da $B$. controle destas espécies (Figuras 3 e 4). ruziziensis durante o desenvolvimento do milho Entretanto, deve-se desenvolver estratégias de safrinha promoveu significativa redução da cultivo que evitem também a interferência da $B$. biomassa da comunidade das plantas daninhas e ruziziensis na semeadura e no desenvolvimento consequentemente resultou em excelente das plantas de milho safrinha (Figura 2).

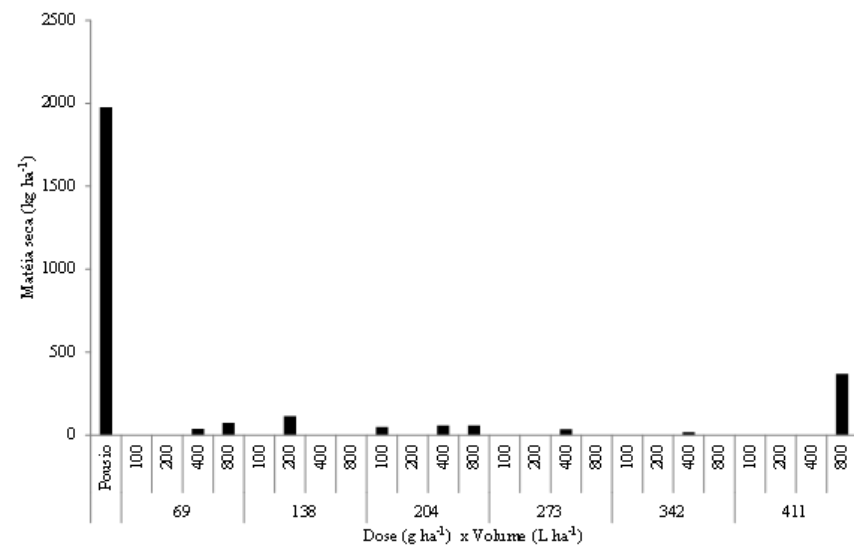

Figura 3.Massa seca das plantas daninhas coletadas após a colheita do milho safrinha, cultivado após a dessecação da $B$. ruziziensis com diferentes doses de paraquat e de volumes de aplicação.

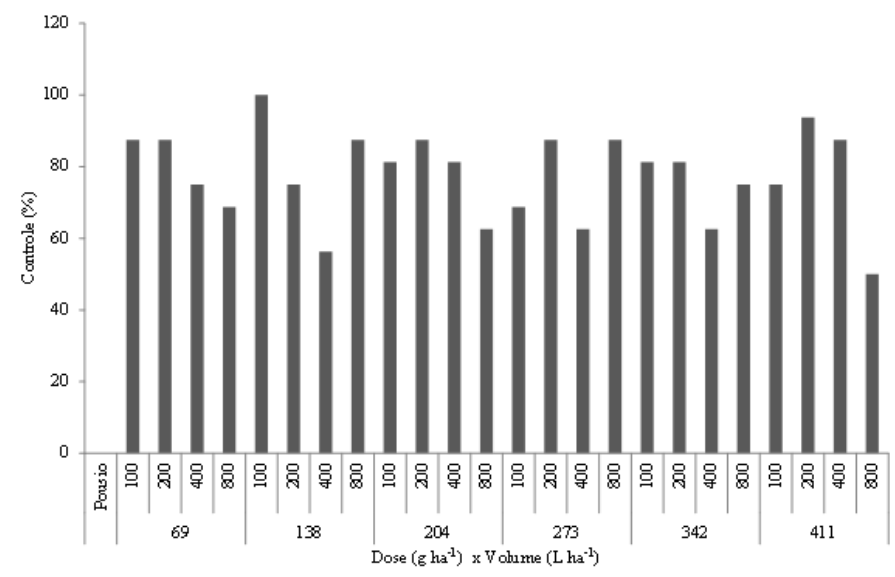

Figura 4. Porcentagem de controle das plantas daninhas após a colheita do milho safrinha cultivado, após a dessecação da B. ruriziensis com diferentes doses de paraquat e de volumes de aplicação. 
Severino et al. (2006b), citam que o sistema de produção que envolve a semeadura de uma cultura forrageira em consórcio com a cultura do milho, em geral, reduz a infestação e suprime o acúmulo de massa seca e área foliar de plantas daninhas no sistema, com destaque para utilização da $B$. brizantha que foi eficiente em reduzir a infestação de corda-de-viola.

Castro et al. (2011), relataram que a presença de $B$. ruziziensis no sistema safraforrageira (soja+braquiária / milho+braquiária / arroz+braquiária/soja) proporcionou a maior redução de massa seca das plantas daninhas e na quantidade de plantas daninhas na área, proporcionando ótimo controle, em relação ao pousio $(97,7 \%)$.

A comunidade das plantas daninhas presente na área experimental foi composta por 11 famílias e 22 espécies, destacando-se as famílias Poaceae, Asteraceae e Euphorbiaceae com seis, cinco e três espécies em cada uma respectivamente (Tabela 6 ).

Tabela 6. Família, nome científico e comum das espécies de plantas daninhas presente na área experimental.

\begin{tabular}{ccc}
\hline Família & Nome Científico & Nome Comum \\
\hline Amaranthaceae & Amaranthus sp. & Caruru \\
\hline & Ageratum conyzoides & Picão-roxo \\
Asteraceae & Bidens pilosa & Picão-preto \\
& Conyza bonariensis & Buva \\
& Macela \\
& Soliva pterosperma & Roseta \\
\hline Commelinaceae & Commelina benghalensis & Trapoeraba \\
\hline Convolvulaceae & Ipomoea sp. & Corda-de-viola \\
\hline & Chamaesyce hyssopifolia & Erva-de-santa-luzia \\
Euphorbiaceae & Croton glandulosus & Malva \\
& Euphorbia heterophylla & Leiteiro \\
\hline Hypericaceae & Hypericum perforatum & Erva-de-são-joão \\
\hline Malvaceae & Sida spinosa & Guanxuma \\
\hline Phyllantaceae & Phyllanthus tenellus & Quebra-pedra \\
\hline & Brachiaria plantaginea & Capim-marmelada \\
& Cenchrus echinatus & Capim-carrapixo \\
Poaceae & Digitaria horizontalis & Capim-colchão \\
& Digitaria insularis & Capim-amargoso \\
& Eleusine indica & Pé-de-galinha \\
& Sorghum halepense & Vassourinha \\
\hline Rubiaceae & Richardia brasiliensis & Poaia-branca \\
\hline Solanaceae & Solanum americanum & Maria-pretinha \\
\hline
\end{tabular}

As espécies $A$. conyzoides, B. pilosa, $C$. benghalensis, D. insularis, S. americanum, Ipomoea sp. e $S$. halepense, também foram encontradas em outras áreas sob sistema de integração agricultura-pecuária (Ikeda et al., 2007; Borghi et al., 2008; Castro et al., 2011; Marchado et al., 2011; Ikeda et al., 2013). Este fato demonstra a possibilidade de seleção de espécies adaptadas ao sistema de integração agricultura-pecuária. Em contrapartida, este sistema de produção pode auxiliar no manejo integrado de espécies comprovadamente tolerantes ou resistentes aos herbicidas a exemplo da Amaranthus sp., B. pilosa, $C$. benghalensis, $C$. bonariensis, D. insularis, $E$. heterophylla e S. halepense (Beckie 2006, Beckie e Reboud 2009, Mello et al. 2012, Vencill et al. 2012; Heap, 2014).

Considerando a economicidade do manejo da dessecação da $B$. ruziziensis pode-se observar que a menor dose do paraquat (100 g $\mathrm{ha}^{-1}$ ) aplicado no menor volume de aplicação 
(69 $\mathrm{L} \mathrm{ha}^{-1}$ ) foi eficiente em dessecar as plantas da forrageira, porém por um curto período. Ressalta-se ainda que o efeito rápido do paraquat na dessecação das plantas seria interessante para ocasiões em haja a necessidade de se iniciar as operações de semeadura da cultura o mais urgente possível, seja por questões operacionais, climáticas ou de zoneamento agrícola. Contudo, mais estudos são necessários para se evitar a interferência da forrageira sobre $\mathrm{o}$ desenvolvimento $\mathrm{e}$ produtividade da cultura em consórcio, sem que ocorra prejuízo na formação de biomassa para o sistema de plantio direto ou para o pastejo de animais.

Herbicidas sistêmicos apresentam efeito relativamente mais lento na dessecação das plantas de B. ruziziensis. Costa et al. (2013), observaram que o glyphosate nas doses de 720 e $1440 \mathrm{~g} \mathrm{ha}^{-1}$ apresentaram eficiência de $93 \mathrm{e}$ 98\% na dessecação desta forrageira a partir dos 28 DAA. Período três vezes superior ao que pode ser obtido com o uso do paraquat no manejo da área para a semeadura da cultura. Outra observação importante foi que devido o rápido efeito do paraquat, as plantas de $B$. ruziziensis ainda permanecem eretas e a palhada em grande quantidade $\left(14.111,8 \mathrm{~kg} \mathrm{ha}^{-1}\right)$ pode ter obstruído o sulco de semeadura e prejudicado a emergência do milho safrinha, ao contrário do que pode acontecer com o uso do glyphosate que apresenta efeito mais lento e permite que a palhada já em processo de decomposição se acomode sobre o solo, facilitando o corte da palha e sem ocorrer obstrução do sulco de semeadura.

\section{Conclusões}

A dessecação da $B$ ruziziensis com paraquat nas doses e volume de aplicação avaliada foram eficientes até aos 14 DAA. A partir dos 14 DAA, as plantas da forrageira iniciaram um novo ciclo de crescimento e interferiram negativamente na produtividade do milho safrinha. A infestação das plantas daninhas foi reduzida nas áreas com $B$ ruziziensis em consorcio com o milho safrinha em relação a área em pousio.

\section{Agradecimentos}

Agradecemos ao $\mathrm{CNPq}$ pela disponibilização do auxílio financeiro para a realização do presente trabalho de pesquisa.

\section{Referências}

ALMEIDA, F.S. Controle de plantas daninhas em plantio direto. Londrina: IAPAR, 1991. 34p. (Circular, 67).

AMARAL, M. Plantio direto evolui no Brasil. Informe Agropecuário, v.22, n.1, p.3-8, 2001.

ARAÚJO, A.G.; RODRIGUES, B.N. Manejo mecânico e químico da aveia preta e sua influência sobre a taxa de decomposição e o controle de plantas daninhas em semeadura direta de milho. Planta Daninha, v.18, n.1, p.151-160, 2000.

BECKIE, H.J. Herbicide-resistant weeds: management tactics and practices. Weed Technology, v.20, n.3, p.793-814, 2006.

BECKIE, H.J.; REBOUD, X. Selecting for weed resistance: herbicide rotation and mixture. Weed Technology, v.23, n.3, p.363-370, 2009.

BORGHI, E. et al. Influência da distribuição espacial do milho e da Brachiaria brizantha consorciados sobre a população de plantas daninhas em sistema plantio direto na palha. Planta Daninha, v.26, n.3, p.559-568, 2008.

CARVALHO, A.J. et al. Desempenho do feijoeiro consorciado com espécies de braquiária em função de doses de fluazifop-pbutil. Planta Daninha, v.30, n.2, p.387-394, 2012.

CASTRO, G.S.A. et al. Sistemas de produção de grãos e incidência de plantas daninhas. Planta Daninha, v.29, n.esp., p.1001-1010, 2011.

CHIODEROLI, C.A. et al. Consorciação de braquiárias com milho outonal em plantio direto 
sob pivô central. Engenharia Agrícola, v.30, n.6, p.1101-1109, 2010.

COSTA, N.V. et al. Avaliação do glyphosate e paraquat no manejo da Brachiaria ruziziensis. Revista Brasileira de Herbicidas, v.12, n.1, p.31-38, 2013.

CUNHA, J.P.A.R. et al. Avaliação de estratégias para redução da deriva de agrotóxicos em pulverizações hidráulicas. Planta Daninha, v.21, n.2, p.325-32, 2003.

DAN, H.A. et al. Supressão imposta pelo mesotrione a Brachiaria brizantha em sistema de integração lavoura-pecuária. Planta Daninha, v.29, n.4, p.861-867, 2011.

DOWNER, R.A. et al. Herbicide spray distribution, quality and efficacy interactions: conflicts in requirements. Aspects Applied Biology, v.1, n.48, p.79-89, 1997.

EMPRESA BRASILEIRA DE PESQUISA AGROPECUÁRIA - EMBRAPA. Sistema brasileiro de classificação dos solos. Rio de Janeiro: 1999. 412p.

FREITAS, F.C.L. et al. Cultivo consorciado de milho para silagem com Brachiaria brizantha no sistema de plantio convencional. Planta Daninha, v.23, n.4, p.635-644, 2005.

FREITAS, R.J.; NASCENTE, A.S.; SANTOS, F.L.S. População de plantas de milho consorciado com Urochloa ruziziensis. Pesquisa Agropecuária Tropical, v.43, n.1, p.79-87, 2013.

GARCIA, C.M.P. et al. Análise econômica da produtividade de grãos de milho consorciado com forrageiras dos gêneros Brachiaria e Panicum em sistema plantio direto. Revista Ceres, v.59, n.2, p.157-163, 2012.

GAZOLA, R.N. et al. Sowing depths of brachiaria in intercropping with corn in no tillage planting. Engenharia Agrícola, v.33, n.1, p.157-166, 2013.

HEAP, I. The international survey of herbicide resistant weeds. Disponível em: <http://www.weedscience.org>. Acesso em: 27 fev. 2014.

IKEDA, F.S. et al. Banco de sementes no solo em sistemas de cultivo lavoura-pastagem. Pesquisa Agropecuária Brasileira, v.42, n.11, p.1545-1551, 2007.

IKEDA, F.S. et al. Interferências no consórcio de milho com Urochloa spp. Ciência Rural, v.43, n.10, p.1763-1770, 2013.

JAKELAITIS, A. et al. Dinâmica populacional de plantas daninhas sob diferentes sistemas de manejo nas culturas de milho e feijão. Planta Daninha, v.21, n.1, p.71-79, 2003.

JAKELAITIS, A. et al. Influência de herbicidas e de sistemas de semeadura de Brachiaria brizantha consorciada com milho. Planta Daninha, v.23, n.1, p.59-67, 2005.

JAKELAITIS, A. et al. Manejo de plantas daninhas no consórcio de milho com capimbraquiária (Brachiaria decumbens). Planta Daninha, v.22, n.4, p.553-560, 2004.

KISSMANN, K.G.; GROTH, D. Plantas infestantes e nocivas. 2.ed. São Paulo: BASF, 1997. Tomo I. 825p.

MACHADO, V.D. et al. Fitossociologia de plantas daninhas em sistemas de integração de sorgo com braquiária sob diferentes formas de implantação da pastagem. Planta Daninha, v.29, n.1, p.85-95, 2011.

MACIEL, C.D.G. et al. Eficiência de paraquat e MSMA isolados e associados a adjuvantes no manejo de plantas daninhas. Global Science and Technology, v.4, n.1, p.70-81, 2011.

MATEUS, G.P.; CRUSCIOL, C.A.C.; NEGRISOLI, E. Palhada do sorgo de guiné gigante no estabelecimento de plantas daninhas em área de plantio direto. Pesquisa Agropecuária Brasileira, v.39, n.6, p.539-542, 2004.

MELLO, L.M.M. et al. Integração agriculturapecuária em plantio direto: produção de forragem e resíduo de palha após pastejo. 
Engenharia Agrícola, v.24, n.1, p.121-129, 2004.

MELO, M.S.C. et al. Alternativas para o controle químico de capim-amargoso (Digitaria insularis) resistente ao glyphosate. Revista Brasileira de Herbicidas, v.11, n.2, p.195-203, 2012.

PORTES, T.A. et al. Análise do crescimento de uma cultivar de braquiária em cultivo solteiro e consorciado com cereais. Pesquisa Agropecuária Brasileira, v.35, n.7, p.13491358, 2000.

RAMSDALE, B.K.; MESSERSMITH, C.G. Adjuvant and herbicide concentration in spray droplets influence phytotoxicity. Weed Technology, v.16, n.3, p.631-637, 2002.

REZENDE, C.P. et al. Alelopatia e suas interações na formação e manejo de pastagens. Boletim Agropecuário, n.54, p.1-55, 2003.

RODRIGUES, B.N.; ALMEIDA, F.S. Guia de herbicidas. 5 ed. Londrina, 2005, 592p.

SBCPD - SOCIEDADE BRASILEIRA DA CIÊNCIA DAS PLANTAS DANINHAS. Procedimentos para instalação,avaliação e análise de experimentos com herbicidas. Londrina: $1995.42 \mathrm{p}$.

SEVERINO, F.J.; CARVALHO, S.J.P.; CHRISTOFFOLETI, P.J. Interferências mútuas entre a cultura do milho, espécies forrageiras e plantas daninhas em um sistema de consórcio. II - Implicações sobre as espécies forrageiras. Planta Daninha, v.24, n.1, p.45-52, 2006a.

SEVERINO, F.J.; CARVALHO, S.J.P.; CHRISTOFFOLETI, P.J. Interferências mútuas entre a Cultura do milho, espécies forrageiras e plantas daninhas em um sistema de consórcio. III - Implicações sobre as plantas daninhas. Planta Daninha, v.24, n.1, p.53-60, 2006 b.

SEVERINO, F.J.; CHRISTOFFOLETI, P.J. Efeitos de quantidades de fitomassa de adubos verdes na supressão de plantas daninhas. Planta Daninha, v.19, n.2, p.223-228, 2001.
SKÓRA NETO, F. et al. Eficácia de herbicidas na dessecação de aveia-preta para formação de cobertura morta em plantio direto. Planta Daninha, v.13, n.2, p.81-86, 1995.

SPRAYING SYSTEMS Co. Teejet: catálogo 50A-P. Wheaton: Illinois, E.U.A., 2008. 192 p. TREZZI, M.M.; VIDAL, R.A. Potencial de utilização de cobertura vegetal de sorgo e milheto na supressão de plantas daninhas em condições de campo: II - Efeitos da cobertura morta. Planta Daninha, v.22, n.1, p.1-10, 2004.

VENCILL, W.K. et al. Herbicide resistance: toward an understanding of resistance development and the impact of herbicideresistant crops. Weed Science, v. 60, n.1, p.230, 2012. 